\title{
El premio de la plata y la devaluación del vellón en Guipúzcoa en el siglo XVII
}

\author{
Álvaro Aragón Ruano y Xabier Alberdi Lonbide *
}

\section{RESUMEN}

El presente artículo analiza la evolución del premio de la plata durante el siglo XVII en Guipúzcoa, donde aparecen dos modelos de comportamiento, siempre en relación con la abundancia y movimiento de la

plata, que es el principal factor que explica las variaciones del premio. Se constata, no obstante, que en cada localidad los premios son diferentes, lo que demuestra la autonomia de las economías locales de Antiguo Régimen. Asi mismo, hay que decir que las mayores repercusiones de este fenómeno se dejaron sentir en los mercados y en las transacciones locales, afectando principalmente a los consumidores. De todas formas, se demuestra la necesidad de seguir realizando investigaciones en los diferentes territorios que formaban la Corona, y desterrar definitivamente la generalización de datos como los de Hamilton.

\section{ABSTRACT}

The next article analises the evolution of the silver's prize during the XVIIth Century in Guipuzcoa, where there arise two trends of behaviour, always related to the movement and abundance of the silver, which are the main factors that explain the changes of the prize. It is verified, nevertheless, that in each town the prizes are different, which shows the local economies' autonomy in the Ancient Regime. Besides, we should add that the main repercussion of this phenomenon was reflected in the local markets and transactions, mainly affecting the communities. In any case, it is stated the need to continue investigating in the different territories which formed the Crown, and to stamp out definetely the generalization of data, such as Hamilton's one.

* Universidad del País Vasco. 


\section{INTRODUCCIÓN}

Earl Hamilton estableció los valores que alcanzó el premio de la plata en la región andaluza, basándose en las contabilidades de la Casa de Contratación y del Hospital de la Sangre de Sevilla. Pero sus estimaciones, válidas como punto de referencia, han sido extrapoladas a cualquier ámbito. A pesar de todas las revisiones que, desde hace treinta años, se vienen haciendo de las tesis de Hamilton, sobre la revolución de los precios, se siguen aplicando sus cálculos referentes a los problemas monetarios del siglo XVII. Como bien afirma Elena Maria García Guerra ', dejando a un lado que la historia económica o serial están de "capa caída", un estudio en profundidad sobre esta materia requeriría mucho tiempo, paciencia, labor de equipo y financiación. La mayoría de historiadores asumen los datos por necesidad o por considerar que está todo dicho.

Es una constante en la historiografía guipuzcoana y vasca, el miedo casi atávico al análisis del siglo XVII. El análisis del siglo XVII en las provincias vascas y, más concretamente, en Guipúzcoa está lleno de interrogantes, pero al mismo tiempo de mitos y extrapolaciones: no existe un solo estudio específico sobre esta cronología; los historiadores guipuzcoanos se han limitado a reafirmar la supuesta "crisis" que pareció afectar a todo el occidente europeo, sin realmente comprobar si esa realidad era extrapolable al ámbito guipuzcoano.

Esa misma realidad es la que ha hecho poco atractivo el estudio del siglo XVII. Acostumbrados al canto de gestas y grandezas, imbuidos de una fuerte impronta ideológica, fuese del signo que fuese, los historiadores han rehuido investigar un siglo de supuestas miserias, crisis económica y retroceso del Imperio castellano, como si ello fuese aplicable en el caso de Guipúzcoa. A ello hay que sumarle un aspecto práctico: la documentación del siglo XVII es ciertamente abundante, a veces de difícil lectura (sobre todo cuando la letra es procesal) y mal conservada.

Por tanto, las preferencias a la hora de estudiar la historia moderna de Guipúzcoa han sido el siglo XVI y el siglo XVIII. El primero como ex-

Garcia Guerra, E.M., "Las mutaciones monetarias en el siglo xvi!. Consideraciones en torno a su estudio", Cuadernos de Historia Moderna, núm. 14 (1993), p. 247. 
presión del auge de la economía y sociedad guipuzcoanas inmersas en el aparato imperial, y el segundo como reflejo de la recuperación y alumbramiento tras una etapa de oscuridad. Ciertamente, parece que el siglo XVII es un siglo maldito, tema tabú entre los historiadores, a los que parece dar pánico el análisis de una etapa que crítica o no, está llena de matices y realidades aún por descubrir. Precisamente las alteraciones monetarias, que en esta investigación se analizan, constituyen una de esas realidades o acontecimientos poco conocidos en cuanto a su alcance y verdadera repercusión en la economía de los distintos territorios de la Corona. Más aún, en sí mismo, supone un factor más para ahuyentar a los historiadores del estudio del siglo XVII.

En el caso concreto de los problemas monetarios, hay un tercer factor que dificulta el análisis: la falta de fuentes de información propias. No nos referimos a posibles datos de carácter estatal y general, extraídos de los archivos nacionales, formulados en su tiempo por las autoridades imperiales; el gran vacío se plantea a la hora de conocer el alcance real de esos problemas en Guipúzcoa y en cada una de sus villas y lugares: lo que interesa realmente es comprobar si el caso castellano o el andaluz son extrapolables al caso guipuzcoano. Por otra parte, es necesario indagar acerca de las verdaderas repercusiones de este fenómeno. La historiografía tradicionalmente hace hincapié en las nefastas consecuencias derivadas de las alteraciones monetarias, pero a través de esta labor de investigación se hace patente la necesidad de matizar dichas afirmaciones.

Lo que aquí se plantea no es un trabajo definitivo - ni mucho menos-; se pretende realizar un acercamiento introductorio a través del análisis de una serie de datos localizados en las cuentas municipales de los archivos guipuzcoanos. Es por tanto una muestra, no definitiva, pero real, de cómo vivían estos problemas monetarios las haciendas municipales; creemos que verdadera piedra angular para el conocimiento de la repercusión en las economías locales. En definitiva, se pretende aportar datos hasta ahora inéditos, realizar un estudio introductorio, pero jamás definitivo; a partir de aquí el análisis de los problemas monetarios queda abierto para los investigadores, a lo cual se les invita.

Las fuentes documentales responden a una realidad y a una necesidad del momento determinado en el que surgen, por eso, desde el punto de vista de un investigador actual, pueden resultar insuficientes para el conocimiento. Los datos aportados por las cuentas municipales están llenos de limitaciones. A diferencia de las series establecidas por 
Hamilton o Serrano Mangas, los datos no son diarios o mensuales; muy al contrario, anualmente aparecen uno o dos datos - a lo sumo cuatro--, sin especificar la fecha exacta. La existencia de datos en las cuentas municipales depende de la aparición aislada de cantidades expresadas en plata, que son reconvertidas a vellón, moneda con la que las instituciones municipales trabajan regularmente, en el día a día. Lo cierto es que la moneda de plata será el punto de referencia para establecer los precios y para comerciar con el exterior, mientras que la mayor parte de las transacciones internas se realizarán en vellón?

Los datos aportados no son geográficamente equilibrados, pues no lo permite el estado actual de los archivos (algunas cuentas municipales no están completas), ni los propios datos referenciados en dichas cuentas municipales; en muchos casos, aparecen datos aislados de los que no se pueden extraer series. Figura representada la mayoría de la provincia, excepto el sector oriental costero. Se han encontrado datos en Fuenterrabía, Hernani, Asteasu, Pasajes, Zumárraga, Ordicia, Azpeitia, Urrechu, Vergara y Segura, aunque se consultaron otros archivos como Deva, Mondragón, Motrico o Tolosa, pero sin resultados.

A pesar de todas las limitaciones, creemos que los datos que aquí se presentan pueden gozar del interés de los investigadores, a los que pueden ayudar de un modo práctico en cada caso y a nivel general en toda Guipúzcoa, puesto que los casos son suficientemente representativos dentro del entramado económico guipuzcoano y aparecen representadas las áreas económicas y comerciales más importantes: Pasajes y su entorno, el curso medio del Oria, el curso medio del Urola y el curso medio del Deva.

\section{ESTADO DE LA CUESTIÓN}

Elena María García Guerra ${ }^{3}$ advierte del desinterés que el tema ha creado entre los historiadores a nivel estatal por considerarlo monótono

Garcia Guerra, E.M., «Alteraciones monetarias. Arbitrismo y comercio en el siglo xvil», ENCISO RECIO, L.M., La burguesía española en la Edad Moderna. Valladolid, Universidad de Valladolid-Fundación Duques de Soria, 1996, Tomo II, p. 633; Serana Mangas, F., Vellón y metales preciosos en la corte del rey de España (1618-1668). Madrid, Banco de España, 1996, p. 18.

\footnotetext{
Gaficia Guerra. E.M., Las mutaciones..., op. cit., pp. 243-254.
} 
y complicado. Los tradicionales trabajos de Hamilton siguen hoy manteniendo su vigencia; su mejor aportación parece ser la serie sobre el valor del premio de la plata en Andalucía para el período 1604-1660 ${ }^{4}$, y los premios de la plata en Andalucia, Castilla la Nueva y Castilla la ViejaLeón (1620-1650) ${ }^{5}$, publicadas por primera vez hacia 1948, utilizando las Secciones de "Diversos de Castilla», "Contadurías Generales" y "Tribunal Mayor de Cuentas" del Archivo General de Simancas. También Antonio Domínguez Ortíz hizo su aportación hacia 1960, basándose en la memoria del Contador Tomás de Aguilar, en la Sección de "Consejo y Juntas de Hacienda" del Archivo General de Simancas, y en la Sección de "Consejos Suprimidos" del Archivo Histórico Nacional ${ }^{6}$.

Tras ellos, en la década de los años setenta destacan los trabajos realizados por Esteban Collantes y José Patricio Merino Navarro ${ }^{7}$, en los que realizan un estudio de las alteraciones monetarias en Castilla, durante el reinado de Carlos II, entre 1665 y 1686, tratando así de cubrir el vacío dejado por los anteriores autores: realizan un análisis de la legislación que la monarquía plantea para superar los problemas y los cambios operados tanto en el valor real como nominal de las monedas, hasta llegar a los años 1680 y 1686 , en los que se logra cierta estabilidad.

$Y$ así, con estos presupuestos se ha venido trabajando también en la década de los años ochenta, donde no hay preocupación por estos temas, y se asumen de forma acrítica los datos aportados hasta el momento. En la década de los noventa, parece que el panorama cambia. Elena María García Guerra ${ }^{8}$ inaugura este período, tratando de analizar cómo afectaron las alteraciones monetarias a la actividad comercial de la burguesia. Juan Sánchez Belén ${ }^{9}$ analiza los proyectos arbitristas

Hamiton, E.J., El florecimiento del capitalismo. Madrid, Alianza, 1984.

5 Idem, El tesoro americano y la revolución de los precios en España. Barcelona, Ariel, 1983.

6 Dominguez Ortiz, A., Politica y hacienda de Felipe IV. Madrid, Ed. Derecho Financiero, 1960.

Collantes Pérez-Ardá, E.-Merino Navarro, J.P., “Alteraciones al sistema monetario de Castilla durante el reinado de Carlos II», Cuadernos de Investigación Histórica, núm. 1 (1977), pp. 73-98; Idem, “Política monetaria de Carlos II: Alteraciones en el sistema castellano", Acta Numismática, núm. 8 (1978), pp. 221-249.

8 Garcia Guerra E.M., Alteraciones monetarias..., op. cit., pp. 633-647; Idem, “La moneda de vellón: un instrumento al servicio de la fiscalidad del Estado moderno castellano: las Cortes", Cuadernos de Historia Moderna, núm. 21 (1998), pp. 59-101.

9 SÁNCHEZ BeléN, J.A., "Arbitrismo y reforma monetaria en tiempos de Carlos Il", Espacio, Tiempo y Forma, núm. 5 (1992), pp. 135-176. 
planteados al monarca para reformar el sistema monetario. Jesús Bravo Lozano ${ }^{10}$ analiza la devaluación del 10 de febrero de 1680 y sus repercusiones, fijándose en la circulación monetaria de los noventa pueblos que integraban la jurisdicción de Madrid y, por fin, se da cuenta de que los datos de Hamilton no son extrapolables al hinterland de Madrid, más aún, se pregunta si en el resto de la Corona de Castilla se reproduce el modelo planteado por él en Madrid; por tanto, sospecha que hay diferencias regionales, llegando a constatar los diversos ritmos de la "crisis" del siglo XVII.

Carlos Vera García y Mercedes García Martínez "1 vuelven a realizar un análisis de las repercusiones en el mercado de las variaciones de la moneda de vellón, sus resellos en la Corona de Castilla entre 1642 y 1650 , volviendo a utilizar datos como los aportados por Hamilton o García Caballero, que, según explican, no están contrastados y ordenados. Felipe Ruiz Martín ${ }^{12}$ advierte de las diferencias entre la Corona de Castilla y la de Aragón, donde a través del sistema de "cambios» sanean la moneda y se salvan de la plaga del vellón.

Serrano Mangas ${ }^{13}$ incide en las diferencias regionales, sobre todo, entre el centro de poder político y, por ejemplo, Sevilla, como receptor de los metales preciosos americanos, aportando datos entre 1619 y 1668. Lo más importante son las aseveraciones que realiza con respecto al País Vasco; dice concretamente:

"Quisieramos esbozar el contraste, la antítesis de la circulación del veIlón. Dentro del ámbito castellano, sólo una zona mostró un comportamiento atípico en lo que se refiere a la relación entre la plata y el vellón. Esta conducta anómala sería, en el fondo, la consecuencia de la existencia de impedimentos para el total dominio de la mala moneda. El País Vasco, que era ese distrito, contaba con una apreciable industria de fundición y administración del hierro, con una industria naval que se hizo hegemónica en la Carrera de Indias, con mentalidad evolucionada y distinta de la del resto de

10 Bravo Lozano, J., "La devaluación de 1680. Propuesta de análisis", Hispania, 183 (1993), pp. 115-146.

11 Vera García, C.-García Martínez, M., "Las modificaciones del vellón y su influencia en el precio de la plata en Castilla (siglos XVI y XVII)", Actas IX Congreso Nacional de Numismática, Elche, 1994, pp. 369-380.

12 Martin Ruiz, F., «El problema del vellón: su incidencia en la distinta evolución económica de Castilla de la Corona de Aragón en el siglo XV||», Manuscrits, núm. 15 (1997), pp. 97104.

13 Serrano Mangas, F., op. cit. 
los castellanos y con relaciones mercantiles y financieras ramificadas por todo el planeta. Propiciaba todo ello que la salud económica de los vascos obstaculizase el imperio del numerario del vellón...Prácticamente ignoramos casi todo sobre la circulación de la mala moneda en el País Vasco. Aventurado y temerario sería, por nuestra parte, lanzar cualquier hipótesis al respecto...insistimos en que tiene peculiaridades propias».

Es este el panorama que a nivel estatal tienen los estudios sobre las alteraciones monetarias del siglo XVII. En líneas generales, la mayoría de ellos se centra en aspectos legislativos y en las repercusiones que dichos fenómenos tuvieron, a efectos prácticos, sobre la economía y los principales grupos económicos. Todo ello bajo un prisma globalizador en el que los datos se extrapolan desde Andalucía o Madrid al resto de territorios. No obstante, lo cual es esperanzador, algunas voces se alzan advirtiendo de las más que probables diferencias geográficas y de la necesidad de realizar nuevos y profundos estudios en cada uno de los casos. Como bien señala Serrano Mangas la clave de las diferentes situaciones parece estar en el mayor o menor dinamismo económico y comercial de cada región y en la mayor o menor circulación de plata.

En lo que se refiere al caso del País Vasco y, más concretamente, a Guipúzcoa, el panorama es desolador, puesto que es un tema aún virgen. A través de estas líneas se pretende establecer un esbozo introductorio que, sin duda alguna, debería venir continuado por estudios de más hondo calado en los próximos años - al menos, si la documentación lo permite-.

\section{DIFERENCIAS GEOGRÁFICAS}

Se perciben dos comportamientos bien diferenciados, pudiéndose hablar de un modelo marítimo o costero y de un modelo interior.

\subsection{Localidades Marítimas}

\subsubsection{Fuenterrabía}

Los primeros datos que aparecen en las cuentas municipales son de 1642. En esos momentos el premio de la plata se situaba en un $150 \%$, alto si se compara con los datos aportados por Serrano Mangas 
o Hamilton, que sitúan la media en 124 ' $87 \%$ y $120 \%$ respectivamente. Para 1644-1645 el porcentaje se sitúa en el 25\%, más bajo que en el caso de ambos autores. En la década de los cincuenta, el premio queda fijado, como en Castilla y Andalucía, en el 50\%, pero con importantes variaciones en algunos casos ( $18 \%, 44 \%$ y $62 \%$ ), cuando en Castilla y Andalucía parece mantenerse estable entre 1649 y 1656. En la década de los sesenta, el premio en Fuenterrabía se sitúa por debajo de lo expresado en Madrid, aunque para finales de 1668 se acerca al $135 \%$. Los máximos parecen darse entre 1672 y 1677 , cuando alcanzan el $177-183 \%$. Para el año 1681 el premio se estabiliza en torno al $50 \%$ y así perdura a la entrada del siglo XVIII. Un dato curioso y excepcional, si lo comparamos con el comportamiento mostrado por otras localidades, es que entre 1683 y 1684 el premio varia entre el 47 y el $59 \%$, aunque para 1685-1686 parece estabilizarse, tal vez por influjo de las disposiciones de $1686{ }^{14}$. El porqué del mayor influjo de la legislación en el caso de Fuenterrabía debe buscarse en la mayor circulación de plata, y en una mayor influencia de los acontecimientos y vaivenes sufridos por la Corona; no en balde, Fuenterrabía era un centro comercial muy dinámico y principal plaza fuerte fronteriza frente a Francia.

\subsubsection{Pasajes}

Los datos se extienden desde 1629 hasta 1684. Ya para esa fecha el porcentaje es netamente superior al aportado por Serrano Mangas en el caso de Madrid (14'68\%) y Hamilton en los tres casos de Andalucía, Castilla la Mancha y Castilla la Vieja-León, aunque en la década de los treinta sí se acerca a los mismos. Como en el caso anterior y otros posteriores que iremos viendo, los cambios y subidas más importantes se producen a partir de 1655. En la mayor parte de los casos, los porcentajes son superiores a los descritos por Serrano Mangas. En Pasajes el mayor premio se concede en 1679 con un $188 \%$ de premio. En 1680 se estabiliza en torno al 50\%. De todas formas, a partir de 1670 el premio muestra una gran estabilidad en torno al $150-175 \%$. Quizás la característica más destacada de Pasajes sea su tendencia a la estabilidad (1638-1640 - 50\%; 1649-165950\%; 1669-1670 - 175\%; 1673-1678 - 175\%); síntoma de una mayor 
accesibilidad a la plata, pues esta localidad se ubica en el principal puerto guipuzcoano.

\subsubsection{Hernani}

Desgraciadamente los primeros datos aparecen en 1657. Las variaciones con respecto a los datos de Serrano Mangas son ostensibles. Son de destacar las oscilaciones registradas; en aquellos casos en los que aparecen dos o más datos, las diferencias son ciertamente importantes. Como en los casos anteriores, a partir de 1665-1666 el premio se eleva, llegando a alcanzar un máximo de $175 \%$.

Llegados a este punto, es necesario hacer una serie de precisiones con respecto al «modelo marítimo»:

Los máximos premios alcanzados no llegan ni sobrepasan el $200 \%$, como sí ocurrirá en el caso del «modelo interior». Por tanto, en las localidades marítimas el premio de plata será inferior al alcanzado en el interior, posiblemente porque en estas localidades marítimas la plata sería más abundante, gracias a las transacciones comerciales que se realizaban. A este respecto, destaca el hecho de que la práctica totalidad de las compraventas de productos extranjeros (cereales, vino, manufacturas, etc.) y propios (hierro, grasa de ballena, etc.) que se realizaban en las villas portuarias, utilizaban moneda de oro y plata, que eran las únicas aceptadas por los extranjeros y por los inversores y empleados en actividades marítimas, caso de las pesquerías transoceánicas, el corso o el comercio marítimo. Hecho sobradamente atestiguado por los asientos consignados en los libros de registro de "mercaderías" extranjeras o de renterías o lonjas municipales conservadas ${ }^{15}$. Estas localidades eran además el punto de salida de la plata que, desde América, llegaba a la Península con dirección a Europa ${ }^{16}$. No resulta fácil

15 Archivo Municipal de Motrico (AMM), Leg. 197: "Libro del cargo del muelle y manifestaciones: fletes" (1582-1619); Archivo Municipal de Zumaya (AMZ), Asuntos Locales: Marina, Ordenanza, etc., Caja 159 (1581-1610); Archivo Municipal de Fuenterrabia (AMF), C, 5, II, 5/1 (1533-1553); C, 5, II, 5/2 (1564-1583); C, 5, II, 5/3 (1583-1589); C, 5, II, 6/1 (1603$1621)$; C, 5, II, 6/2 (1610-1670); C, 5, II, 6/3 (1610-1690).

16 El 14 de octubre de 1624 se expidió una Real Pragmática por la que se prohibía la salida de oro y plata y la entrada de vellón en los reinos de Castilla. El expediente incluye la advertencia del Consejo de Castilla a don Pedro de Alarcón para atajar el daño que la entrada del vellón extranjero producia en los reinos de Castilla. En los Estados rebeldes (Provincias 
calcular la cantidad de plata que salía al extranjero desde los puertos guipuzcoanos, aunque contamos con algunos datos al respecto. Concretamente, si atendemos a las licencias o permisos para introducción de mercancias de contrabando extranjeras, a cambio de moneda de plata, concedidos por la Corona en 1655 , se constata que del total de 5.140.010 ducados de plata autorizados para su extracción, 3.315.828 ducados (el $64{ }^{\prime} 5 \%$ del total) se extrajeron desde San Sebastián ${ }^{17}$; cifra que evidencia la enorme afluencia de plata a los puertos guipuzcoanos y que explicaría la menor repercusión del incremento del premio de la plata en Guipúzcoa. La menor utilización de vellón haría que el premio fuese menor. De hecho en las cuentas municipales utilizadas, aparece mayor número de operaciones realizadas en plata que en el caso de localidades interiores. Como asegura Serrano Mangas, el País Vasco - junto a Cádiz, Sevilla y la Corte - fue el tercer foco de atracción, en la España del siglo XVII, de la plata peruana y mexicana ${ }^{18}$. Donde más

Unidas) se fabricaba gran cantidad de moneda de vellón, que llegaba como mercancía a la Rochela y de allí a Bayona y San Juan de Luz; desde San Juan de Luz se llevaban lanas a la Rochela y Rouen y se traía vellón. Una vez en San Juan de Luz, el vellón entraba de siete formas diferentes en Castilla:

1. Desde San Juan de Luz el vellón se pasaba a Irún en bajamar, pasando luego a San Sebastián, Vergara, Oñate y toda la Provincia, donde se quedaba dicha moneda, para ser introducida en Castilla, bajo el pretexto de ser vellón guipuzcoano.

2. Desde San Juan de Luz, Hendaya y Urruña pasaban diariamente gran cantidad de mujeres "tratantes" a vender "cambraes olandas" en cestones grandes. En dichas cestas traían gran cantidad de moneda de vellón, con el que conseguían pasar por el pasaje de Irún. Una vez pasada, buscaban hombres que se la trocasen por plata.

3. La misma operación era llevada a cabo por aquellos que vendían gallinas.

4. Los soldados de Fuenterrabía pasaban diariamente a San Juan de Luz y Hendaya, donde cambiaban 20 reales de plata por 48 reales en cuartos de vellón.

5. Los arrieros también aplicaban este método

6. Los vecinos de San Juan de Luz que iban a la pesca de ballenas a Noruega, lo hacian en barcos de 300-600 toneladas, con los que no podían entrar en San Juan de Luz, por lo que acudian a San Sebastián y Pasajes a invernar. Los que desde Hendaya o San Juan de Luz les traían mantenimientos durante dicho período, también llegaban con gran cantidad de vellón.

7. Pescadores del País Vascofrancés llegaban en chalupas hasta la altura de San Sebastián, para pescar con "trasmallos" - un tipo de red-, donde en lugares convenidos y senalizados dejaban la moneda, que era recogida por otros cómplices.

El Consejo calculaba que, a través de estos medios, se introducía anualmente un millón y medio de reales de vellón (Archivo General de Gipuzkoa (AGG-GAO), JD IM 1/9/4).

17 Concretamente 3.315.828 ducados desde San Sebastián, 705.600 ducados desde Cádiz, 311.546 desde Ágreda, 211.000 desde San Lúcar, 195.000 desde Sevilla, 177.000 desde Málaga, 120.000 desde Bilbao, 70.000 desde Motril, 26.581 desde Laredo y 7.455 desde Logroño (Archivo General de Simancas (AGS), Contaduría del Sueldo, $2{ }^{\circ}$ Serie, Leg. 139).

is Serrano Mangas, F., op. cit., p. 36. 
plata habrá será en la costa y no en el interior. La existencia de más plata y el hecho de que corriese con más fluidez en la costa hace que se pague menor premio. Para el caso de Madrid, Bravo Lozano insiste en la misma realidad: en el medio urbano se dan transacciones comerciales más abundantes e intercambios con el extranjero, para lo que lógicamente se necesita oro y plata, mientras que el autoabastecimiento predomina en el medio rural, por lo que no es tan necesaria y predomina el vellón ${ }^{19}$; siguiendo la ley de Gresham, la moneda mala desplaza la moneda buena: la circulación interna queda prácticamente reducida a vellón ${ }^{20}$. Sin embargo, en el interior, donde la plata será más escasa, el premio alcanzará mayores cotas, al ser este metal precioso más deseado. Puesto que la plata no es sólo moneda de cambio, sino también objeto de comercio, porque, como afirma Collantes, el metal es al mismo tiempo una mercancia ${ }^{21} y$, como tal, sobre el valor del dinero actuarán la oferta y la demanda. Nos parece acertada la afirmación de Serrano Mangas ${ }^{22}$ cuando dice que "Es posible que la aminoración del premio venga impuesta por la abundancia de plata en la plaza gaditana...".

Los datos se parecen a los dados por Hamilton en Sevilla, aunque con diferencias. Estos datos están más relacionados con los factores que influyen en aquel caso: las disposiciones legales, la recepción de plata y oro indianos y los conflictos bélicos, que afectaban sin duda el normal desarrollo del comercio.

\subsection{Localidades del interior}

\subsubsection{Cuenca del Oria}

Engloba los casos de Asteasu, Ordicia y Segura. Curiosamente en el caso de Asteasu, de todas formas cercano a San Sebastián y centros costeros como Orio o Zarauz, los premios son menores a los registrados en Ordicia o Segura. En este último caso, en el año 1642

19 Bravo lozano, J., op. cit., p. 123.

20 Ruiz Martin, F., op. cit., p. 101.

21 Collantes Pérez-Ardá, E.-Merino Navarro, J.P., Política monetaria..., op. cit., p. 224.

22 Serrano Mangas, F., op. cit., p. 25. 
encontramos que se conceden premios tan altos como el de $150 \%$ o el de $213 \%$, lo cual es una cifra desorbitada para el momento y demuestra que el precio se negociaba a pie de calle. Un dato curioso que no hemos querido dejar de reflejar es el de que en Ordicia entre 1646 y 1651 se trabaja en las cuentas en reales de 36 maravedis y no de 34 maravedís, aunque entre 1651 y 1655 se trabaja con los dos.

\subsubsection{Cuenca del Urola}

Las cifras de Zumárraga, Urrechu y Azpeitia demuestran ser superiores a las registradas en la Cuenca del Oria, siendo la franja donde mayores cotas alcanza el premio de la plata (213\% y $230 \%)$, ya para 1675-1676. Una vez más, se confirman las diferencias geográficas, incluso entre localidades vecinas: si bien los datos aportados por las cuentas municipales de Urrechu no son abundantes, vemos que esta localidad llega a mayores cotas que Zumárraga y que la estabilización se produce de forma más tardía. El caso de Azpeitia es ciertamente esclarecedor: el dato de 1630 nos indica que no se había comenzado a aplicar el premio de la plata, como ya venía ocurriendo en Andalucía o Madrid, lo cual indica una mayor estabilidad económica y tardía entrada de la "crisis", hasta al menos 16291630 , en el caso guipuzcoano.

\subsubsection{Cuenca del Deva}

En esta ocasión sólo contamos con los datos aportados por las cuentas municipales de Vergara. Las cifras comienzan a aparecer en 1632 y para 1671 desaparecen. De todas formas, se mantienen en niveles más bajos que los del Urola o el Oria. Este menor crecimiento del premio de la plata en Vergara, en relación a las demás localidades del interior de la provincia, puede constituir un ejemplo más a favor de las hipótesis planteadas en este trabajo. Esta villa, ubicada en la cuenca dei río Deva, una de las principales rutas de comunicación del interior peninsular con los puertos guipuzcoanos, constituía uno de los principales mercados comarcales de Guipúzcoa. Allí se comercializaba el trigo procedente de Castilla y se centralizaba el hierro en bruto fabricado en las cuencas del Urola, Deva y sector oriental de Vizcaya, destinado tanto a su exportación a Castilla por tierra como a abastecer las industrias de manufacturas férricas de las cuencas altas del Urola y 
el Deva ${ }^{23}$. En suma, un activo mercado al que llegaría la plata con mayor asiduidad y abundancia que a otras localidades del interior guipuzcoano, lo que se traduciría en un menor incremento de su valor.

En definitiva, la menor circulación de moneda de plata en el interior de Guipúzcoa provoca que se alcancen mayores cotas en el premio; es decir, la plata sufría una supravaloración en el interior, debido a su escasez. Más aún, ello mismo provoca que las oscilaciones en una misma fecha sean mayores, esto es, que el real de plata se pague a distintos precios, con grandes diferencias, lo cual así mismo demuestra que el premio varía en función de los negociadores. En el caso de Madrid, el propio Cosme Micón, que es el autor del memorial que utiliza Serrano Mangas, asegura que «...acontecia que algunas personas se daban tanta prisa que tomaban su plata debajo de la capa y se iban de casa en casa rogando con ella o buscando con tantas ansias que cuando hallaban su ocasión no la perdían aunque fuese con gran diferencia del premio que corría de tal manera que sucedia que en un barrio se trucaba a dos, a cuatro, a seis y a más por ciento de lo que en otro corría" ${ }^{24}$.

A nivel global, parece que en Guipúzcoa las cotas alcanzadas por los premios superan las registradas en Madrid y Andalucia, y en ello coincide Serrano Mangas ${ }^{25}$, no por la escasez de plata, sino por el rechazo del vellón. Así parece ocurrir hasta al menos 1669, pero a partir de entonces las cifras se muestran más estables e inferiores a las registradas en el resto, pues en 1677 llegó al 212\% y en vísperas de la reforma monetaria de 1680 al $275 \%{ }^{26}$, mientras que en Guipúzcoa el máximo localizado es de $230 \%$. Tal vez ello se pueda explicar por una mayor presencia de la plata en Guipúzcoa, justo cuando las flotas que traen la plata americana ya no son anuales y cuando se empiezan a hacer viajes particulares para traerla.

Puede que la «crisis» y la repercusión de las alteraciones monetarias llegaran más tarde a Guipúzcoa, pues los primeros sintomas no

23 Al respecto véase: ALBERDI LONBIDE, X., "El proyecto de compañía de comercialización del hierro a principios del siglo XVIII", en Historia de Oñati: siglos XIV-XVI. Oñate, Ayuntamiento de Oñate, 1999, pp. 159-179; AzPIazu Elorza, J.A., Sociedad y vida social vasca en el siglo xvi. Mercaderes guipuzcoanos. San Sebastián, Kutxa, 1990,Vol. 1, pp. 170-176 y Vol. 2, pp. 36-59.

24 Serrano Mangas, F., op. cit., p. 12.

25 Ibidem, p. 36.

26 SÁnchez BelÉn, J.A., op. cit., p. 139. 
aparecen hasta 1629, con diferencias geográficas. También duró más y, si en Madrid y Andalucía la estabilidad se logró plenamente en 1680, algunos lugares como Fuenterrabía, Asteasu o Azpeitia tardaron un año más, pues hasta 1681 no lograron estabilizar el premio en el 50\%.

Atendiendo a la evolución del premio de la plata durante el siglo XVII en el conjunto de localidades estudiadas, se constatan dos fases de crecimiento importante, alternadas por fases de descenso. No parece que en el caso guipuzcoano haya que buscar los mismos factores que, por ejemplo, afectaron a Madrid. Las dificultades financieras de la administración de Felipe IV entre 1625 y 1628, derivadas de la situación internacional y de la agobiante presión holandesa sobre la plata americana, no parecen afectar a Guipúzcoa. Tras un período en el que la práctica totalidad de los porcentajes del premio se mantienen por debajo del $50 \%$, hacia 1635, coincidiendo significativamente con el inicio de la guerra entre Francia y la Corona hispana, se inicia una tendencia alcista que alcanza su máximo, según los casos, entre 1641 y 1643 -coincidiendo con las guerras internas con Portugal y Cataluña, no se olvide. El responsable de este crecimiento puede que fuera la mencionada guerra. Efectivamente, a partir de 1636, en torno a la frontera del Bidasoa, se produjeron los más terribles acontecimientos bélicos sufridos por el País Vasco en todo el siglo XVII: en 1636 la ocupación de San Juan de Luz por las tropas hispanas, apresando el grueso de la flota pesquera de altura labortana; en 1637 invasión francesa del sector oriental guipuzcoano, arrasando los astilleros de Pasajes y apresando varios galeones; en 1638 sitio de Fuenterrabía y destrucción de la escuadra española, comandada por Lope de Hoces, en la batalla de Guetaria, a manos de la escuadra francesa, y en 1639 derrota de la Armada española, en la batalla de las Dunas, a manos de la escuadra holandesa, con las subsiguientes repercusiones de pérdida de hombres y buques ${ }^{27}$.

Las consecuencias sobre la economía guipuzcoana, tal como insiste Luis María Bilbao, en un "país de acarreo" ${ }^{28}$, fueron neíastas. A

27 Rahn Phillips, C., Seis galeones para el rey de España. Madrid, Alianza, 1991, pp. 314-317.

28 Insiste en que el modelo económico del País Vasco atlántico era un modelo «inducido del exterior", que trataba de suplir las carencias del sector primario por medio del desarrollo de los sectores secundario y terciario (BILBAO, L.M., "Transformaciones económicas en el Pais Vasco durante los siglos xvı y xVII», en Historia del Pueblo Vasco, $n .^{\circ} 2$, San Sebastián, Ereiri, 1979, pp. 134-143). 
modo de ejemplo, en lo que a las pesquerías transoceánicas de ballenas y bacalao se refiere, entre 1636 y 1637 no se aprestó ninguna embarcación, en 1638 sólo una y en 1639 dos ${ }^{29}$. Precisamente en 1639 se tuvo que recurrir a la obtención de medidas legislativas, eximiendo a los pesqueros de la obligación de servir en la Armada y rebajando los impuestos al pescado aportado ${ }^{30}$, al objeto de fomentar la reactivación de la actividad. La construcción naval también experimentó una recesión a partir de 1639 , que se extendió durante una década ${ }^{31}$. En lo referente a los productos férricos vascos exportados a Indias, se constata un destacado descenso que culmina en la década de los años treinta del siglo XVII ${ }^{32}$.

En suma, los valores más elevados del porcentaje del premio coincíden con la crítica coyuntura económico-bélica expuesta. Al margen de las localidades del interior, que en general experimentan las cifras más elevadas, de entre las del litoral destaca el caso de Fuenterrabia. Puede que el desmesurado crecimiento experimentado por el premio de la plata en esta localidad -que alcanza su máximo en 1642, comọ muestra del final de una situación coyuntural- se deba precisamente a los terribles acontecimientos descritos, que le afectaron de manera muy directa y evidente. Por tanto, dentro de las diferencias entre localidades del interior y de la costa, la «excepción» de Fuenterrabía serviría para confirmar la hipótesis de que el mencionado auge del premio de la plata sería una consecuencia de la coyuntural crisis económica y bélica, que provocó la disminución del tráfico mercantil y, por tanto, de la disponibilidad de plata en Guipúzcoa, lo que repercutiría en su «encarecimiento».

A partir de los primeros años de la década de los cuarenta, coincidiendo con la incipiente reactivación de la economía guipuzcoana ${ }^{33}$, se

\footnotetext{
29 Archivo del Museo Naval (AMN), Colección Vargas Ponce, T. III, doc. 72.

30 AGG-GAO, JD IM 2/12/31 (P5D17).

31 OdRIOzOLA L., "La construcción naval en Gipuzkoa. Siglos XVI-XVIII», Itsas Memoria, núm 2 (1998), p. 102.

32 GARCIA FUeNTES, L., Sevilla, los vascos y América. (Las exportaciones de hierro y manufacturas metálicas en los siglos $x v i, x v I l$ y xvIII). Bilbao, Fundación BBV, 1991, p. 218.

33 Esta reactivación es evidente en algunos de los sectores económicos ya mencionados. En cuanto a las pesquerias transoceánicas, el número de pesqueros armados en 1643 ascendía ya a seis (AMN, Colección Vargas Ponce, T. III, doc. 72). En cuanto al comercio, se constata un aumento de las exportaciones férricas a Indias durante la década de los cuarenta (GAacia Fuentes, L., op. cit., p. 218) y, merced al permiso concedido por el rey en 1644, se
} 
produjo un brusco descenso del premio de la plata, por debajo del $50 \%$. En la década de los años cincuenta, propiciado quizás por el fin de la Guerra de los Treinta Años en 1648, se acentuó la bonanza económica. Debió también contribuir la firma del Tratado de Conversa de 1653 entre Guipúzcoa, Vizcaya y Labort, que aseguraba el libre comercio entre los territorios vascos sometidos a la soberanía española y francesa ${ }^{34}$. A pesar de que García Fuentes aprecia un descenso de las exportaciones férricas a Indias durante la década de los cincuenta ${ }^{35}$, no ocurre lo mismo con el resto de actividades. Así en 1655, había en Guipúzcoa unos 18 pesqueros dedicados a las pesquerías transoceánicas de ballenas y bacalao ${ }^{36}$. Lourdes Odriozola señala la existencia de otra fase de auge en la construcción naval guipuzcoana, que se extiende desde la década de los cincuenta hasta los años ochenta ${ }^{37}$.

La bonanza de los cincuenta se materializó en la estabilidad alcanzada por el premio de la plata en torno al $50 \%$. A partir de la segunda parte de la década, se inició un leve aumento de los premios, tendencia que se acentuó en la década de los sesenta. Los valores máximos se alcanzaron en todos los casos durante la década de los años setenta. A simple vista, teniendo en cuenta, como se acaba de mencionar, que estas dos décadas fueron de crecimiento económico ${ }^{38}$, el gran crecimiento experimentado por los premios de la plata pondría en duda la hipótesis aquí planteada, que vincula la bonanza económica con el descenso del premio. Hipótesis que aún se debería matizar más, si se considera que el inicio del crecimiento del premio coincidió con la paz de los Pirineos (1659), que puso fin al enfrentamiento entre Francia y España, restableciéndose las normales relaciones comerciales, que paradójicamente no repercutieron en un descenso del premio. No obstante, se produjeron diversos acontecimientos que en cierto modo debieron repercutir negativamente en la afluencia de plata a la península. La guerra con Inglaterra provocó una crisis pasajera de la

reinició el comercio de bastimentos y pertrechos navales con la Provincia de Lapurdi, bajo soberanía franicesa (AGG-GAO, JD IM 1/10/45).

34 AGG-GAO, JD IM 2/22/41; JD IM 1/10/61.

35 Garcia Fuentes, L., op. cit., p. 218.

36 AGG-GAO, JD IM 2/12/34; Ciriquiain Gaiztarro, M., Los vascos en la pesca de la ballena. San Sebastián, Ediciones Vascas, 1979, p. 300.

37 OdRIOzOLA, L., op. cit., pp. 102-103.

38 Corroborado también por el estudio de las exportaciones de hierro a Indias, que a partir de la década de los sesenta no dejarían de aumentar (GARCia FUENTES, L., op. cit., p. 218). 
Carrera de Indias. El almirante Blake capturó en 1656 parte de los galeones de Tierra Firme y en 1657 en Tenerife la casi totalidad de la flota de Nueva España. Durante tres años quedó colapsado el comercio con Indias y la llegada de plata. Sea como fuere, a partir de estas fechas el ritmo de las flotas de Indias dejaría de ser anual ${ }^{39}$, lo cual debió repercutir en la disminución de la disponibilidad de plata. A este respecto, es un hecho significativo la aparición de pleitos suscitados en torno al comercio directo con Indias, que se pueden encontrar en los fondos del Corregimiento de Guipúzcoa. Dichos fondos engloban los procesos de segunda instancia dirimidos en el tribunal del Corregidor de Guipúzcoa, a lo largo de toda la Edad Moderna. De entre todos sus procesos, se han localizado nueve pleitos relativos al comercio directo con Indias, tanto de navíos de registro como de contrabando. Todos ellos, salvo uno de 1714, pertenecen al siglo XVII. Es más, significativamente pertenecen todos a las décadas de los años sesenta y setenta del mismo ${ }^{40}$. La aparición de este tipo de pleitos es síntoma del aumento de los intercambios directos de los comerciantes guipuzcoanos y extranjeros, asentados en la provincia, con las Indias, ya sea de forma legal o ilegal. En suma, la disminución de la frecuencia de las flotas de la Carrera de Indias coincide con el incremento de este tipo de navegaciones particulares. En definitiva, puede que el aumento del premio de la plata experimentado durante las décadas de los años sesenta y setenta tenga relación directa con las transformaciones acontecidas en el tráfico comercial con indias, que presumiblemente debieron traducirse en una disponibilidad de plata más irregular en Guipúzcoa - no obstante, más regular que en el resto de la Corona, gracias a los mencionados intercambios directos con Indias-, lo que desembocaría en su "encarecimiento".

Este proceso se interrumpió bruscamente en 1680, cuando el premio de la plata se estabilizó - de forma artificial y gracias a la Corona-, en torno al $50 \%$. La reforma monetaria aplicada por Carlos II debió tener un efecto inmediato, alcanzando la estabilidad monetaria. De todas formas, de todo lo expuesto, se deduce que la mencionada reforma no fue la única causa de la estabilización del premio de la plata. La buena marcha también de la economía guipuzcoana, iniciada

39 Ibidem, pp. 217-218.

40 AGG-GAO, CO UEJ 515 (1662); CO UEJ 517 (1662); CO ECI 1471 (1662); CO ECI 1474 (1662); CO UCI 613 (1663); CO MEJ 1406 (1664); CO MEJ 1408 (1664); CO MCI 2130 (1672). 
a mediados del siglo, estableció las bases necesarias para el éxito de la aplicación de esta reforma monetaria. Ello se hace patente en el hecho de que la Corona esperase a que se estabilizara la coyuntura político-militar de Europa. Efectivamente, la reforma se emprendió tras la firma de la paz de Nimega (1679), que puso fin a la Guerra de la Gran Alianza (1672-1679), último episodio de los enfrentamientos bélicos que, prácticamente sin interrupción, venían produciéndose desde antes del acceso al trono de Carlos II en 1665.

Otro ejemplo de que la estabilización del premio de la plata se produjo merced al aumento de la disponibilidad de plata, propiciado tanto por la buena coyuntura económica como por la mencionada reforma monetaria, es el hecho de que en 1683-1684 se produjera en Fuenterrabía un leve pero significativo aumento del premio de la plata. Acontecimiento sin parangón, tanto en las localidades guipuzcoanas -aquí estudiadas-, como en otros territorios del Estado. Este hecho debió producirse a consecuencia de la conquista de Luxemburgo por Francia, que desencadenó una nueva guerra entre España y Francia, concluida merced a las presiones de las restantes potencias, en la Tregua de Ratisbona de 1684. Fuenterrabía, una de las principales plazas de defensa de la línea fronteriza pirenaica, sufrió directamente la amenaza francesa, lo que debió provocar una disminución del tráfico comercial de la Ciudad, que se tradujo en la inestabilidad del premio de la plata.

En suma, a pesar de constatarse una evolución general de las tendencias del premio de la plata en las localidades estudiadas, se evidencia una vez más una evolución particular en cada caso, acorde a sus características económicas y coyunturas económico-políticas particulares. Lo que queda claro es que en cada lugar el premio de la plata era diferente, con importantes variaciones de una localidad a otra, por lo que resultaría vano intentar establecer medias o datos unificados para toda Guipúzcoa. Ụn ejemplo claro lo encontramos en las cuentas municipales de Zumárraga, donde, dentro de uno de los asientos contables de 1676-1677 se dice que se reduce,

«...a 22 reales y medio el real de a ocho en San Sebastian y en Segura a 23 y en Vergara a 24 con que vno con otro a respecto de la plata sale a 23 reales el real de a ocho..." ${ }^{41}$,

Archivo Municipal de Zumarraga (AMZu), C/2/2/1, Fol. 305 v. ${ }^{\circ}(1676-1677)$. 
lo que supone un premio de un $175 \%$ en San Sebastián, $188 \%$ en Segura y $200 \%$ en Vergara ${ }^{42}$.

\section{MECANISMOS DE FUNCIONAMIENTO}

\subsection{Negociación de las monedas}

A pesar de que en cada lugar el premio de la plata quedaba fijado en una cantidad en cada momento, lo cierto es que al margen de ello podía ocurrir que quien recibiese el dinero no lo aceptase. Es decir, que en los intercambios y compraventa de productos, el premio de la plata también se negociaba, como lo evidencia este testimonio extraído de las cuentas municipales de Urrechu:

«Primeramente dar en datta mil ducientos y nobenta y seis reales de vellon en diez y ocho doblones que recivimos del alcance echo a los regidores antecedentes a respecto de a setenta y dos reales cada doblon y porque dicha cantidad en la dicha especie se enpleo en la redencion de un censo que esta villa devia de cinquenta ducados de plata de principal a don Antonio de Plazaola quien no quiso recibir los doblones al precio dicho sino a treinta y un reales de platta cargamos a la villa y damos en datta la dicha cantidad los mil ducientos y noventa y seis reales de vellon" ${ }^{43}$.

Por tanto los premios de la plata no son fijos, sino que están al arbitrio de lo que se quiera dar por ella en cada momento. Ello, por supuesto, dependerá de los propios negociadores, su voluntad, situación económica, etc ${ }^{44}$.

42 Los propios autores del texto realizaban una media (175\%), pero con la intención de buscar una cifra intermedia entre tanta oscilación; no es una media provincial, sino la que aplican ellos tratando de optar por una vía intermedia.

43 Archivo Municipal de Urrechu (AMU), Cuentas Municipales, Leg. 2 (1665). Véase asimismo el caso de Madrid, nota $n .^{\circ} 20$. En las cuentas municipales de Zumárraga de 1637 1638 se dice:

"...auian reducido a bellon quatrocientos reales a veinte y ocho por ciento y setecientos y ocho a veinte y çinco por çiento..." (AMZu, C/2/2/1).

44 A este respecto es muy clarificadora la Real Pragmática del 6 de mayo de 1659. Si bien la Real Pragmática de 24 de septiembre de 1658 habia establecido que la moneda de vellón grueso pasase de 2 maravedís a 8, y la Real Pragmática del 30 de octubre de 1658 de 


\subsection{Tipo de moneda utilizada}

A la luz de los datos que aportan las cuentas municipales de los municipios guipuzcoanos, se puede aseverar —como ya se ha hecho- que en el interior de Guipúzcoa la utilización de moneda de plata no era tan habitual, ya que la mayoría de los asientos, desembolsos y cobros realizados por los concejos con particulares se hacen en vellón, puesto que las cantidades que se necesitan son más pequeñas y de menor valor, dentro de un mercado local. No ocurre lo mismo en la costa, en lugares como Fuenterrabía o Pasajes, donde la utilización de moneda de plata es habitual; sobre todo la primera, donde desde 1671 y, sobre todo, desde 1677 todos los asientos se realizan en plata, no en vellón, lo cual es ciertamente sintomático. Esta situación es lógica si se tiene en cuenta que estas localidades contaban con importantes puertos -quizás los más importantes de la provincia - en los que las transacciones con otros países estaban al orden del día, tanto importaciones como exportaciones. Lógicamente, el pago en las transacciones con el extranjero se realizaba en plata, que era la única moneda admitida para este tipo de relaciones comerciales. Precisamente, ambos puertos serán los puntos de llegada de la plata americana-sevillana y de salida final de la península hacia el exterior.

En cuanto a las unidades monetarias, hay que decir que durante el siglo XVII, por regla general $-y$ como demuestran las cuentas municipales-, se utilizó el real -fuese de vellón o plata- de 34 maravedís. Parece que durante el siglo XVI el valor de un real en maravedís variaba geográficamente. Así lo denunciaba en 1569 Esteban de Garibay ${ }^{45}$, quien pedía que en toda Guipúzcoa valiese 34 maravedís, puesto que en Tolosa, Villafranca de Ordicia, Rentería y Hernani valía 36 maravedís,

2 maravedis a 4, la nueva Pragmática redujo la moneda de vellón grueso a la mitad - concretamente la de 4 maravedís pasó a 2 y la de 2 a 1 - debido ai fracaso de las anteriores:

«...mande que este crecimiento, y labor solo se hiciesse, desde dos marauedis a que corria cada pieça, hasta quatro marauedis, y esto se executo como se contiene en la dicha Prematica, y cedula referidas, y aunque al tiempo que se tomo esta resolucion se reconocieron los inconuenientes futuros, que necessariamente auian de resultar d'este crecimiento, no porque la cantidad de el pudiesse desordenar el comercio, sino por la malicia, y codicia de aquellos cuyo trato, y grangeria le tienen librado en la alteracion de los precios de los mantenimientos, y mercaderias, y otras cosas necesarias para el vso del comercio, $y$ en el mayor crecimiento de trueques, y reduciones de la plata y el oro..." (la cursiva es nuestra) (AGG-GAO CO ECI 1432).

45 Archivo Histórico Nacional (AHN), Sección Cámara de Castilla, Serie Patronato Real, Leg. 15651. 
según la ley y valor del Reino de Navarra, en Fuenterrabía e Irún 42, según la ley de Francia. Todo ello perjudicaba a la mayoría de la provincia, pero sobre todo a centros como San Sebastián, Mondragón o Vergara, donde valía 34 maravedís. Ante esta situación la Provincia decretó, a través del Cuaderno de Ordenanzas de 1583, que en la provincia de Guipúzcoa y en todos sus lugares un real de plata o vellón valiese 34 maravedís, como ocurría en Castilla ${ }^{46}$. Parece que el fuero fue cumplido y que se aplicó la equivalencia de 34 maravedís, como parece desprenderse del análisis de las cuentas municipales. Únicamente existe una excepción ya mencionada. En Ordicia, antes de 1650, se viene utilizando el real de 34 maravedís, siguiendo la Ordenanza provincial. No obstante, entre 1646 y 1651 los reales son únicamente de 36 maravedís, siguiendo la ley y valor de Navarra, mientras que entre 1651 y 1655 se utilizan tanto el de 34 como el de 36 . A partir de 1655 se vuelven a utilizar solamente los reales de 34 maravedís. Desconocemos las causas de esta particularidad, pero seguramente tiene que ver con las dificultades monetarias y financieras y con la situación de inflación monetaria, que haría conveniente la utilización de reales de mayor valor nominal; posiblemente se utilizó este subterfugio con el fin de lograr cierta estabilidad. Así parece, puesto que es precisamente a partir de 1656 cuando se deja de utilizar, una vez conseguida la estabilidad en torno al $50 \%$.

\subsection{Procedimientos contables}

En general, los datos contables que aparecen en las cuentas municipales aparecen en moneda de vellón. Por eso, cuando se cita una operación realizada en moneda de plata - no siempre - se reduce a vellón, es decir, se establece la correspondencia en vellón. El problema surge cuando las cifras se dan en plata y en vellón por separado, sin equivalencia alguna, como ocurre, en algunos casos, en Hernani entre 1662 y 1688.

Cuando los contemporáneos expresan el premio de la plata en porcentaje, acostumbran a redondear las cifras. Es decir, si el decimal es menor de 5 se quedan con la cifra anterior, pero si es superior con la posterior. Por ejemplo, si el premio es 1 '431 será el $43 \%$, si es 1 ' 437 será del $44 \%$.

46 Nueva Recopilación de Fueros. Bilbao, La Gran Enciclopedia Vasca, 1975, p. 266. 
Existen al menos tres maneras de expresar la equivalencia o el premio de la plata en vellón:

1. Se da la cantidad en plata pero no se reduce, aunque en el margen se expresa la cantidad de maravedís de vellón o de reales de vellón correspondiente.

2. Se habla de la equivalencia de la moneda de a ocho. Por ejemplo, en las cuentas municipales de Fuenterrabía de 1655, el premio se sitúa en «treze reales el real de a ocho».

3. Se hace la reducción a vellón expresando el tanto por ciento: "Yten reziuieron del capitan Pedro Mateo nobenta reales de plata que hiço de repartimiento por cada soldada de vn biage que hiço a corsso este año próximo passado reduçidos a bellon a 25 por çiento hazen ciento y doze reales y medio" ${ }^{47}$.

Trabajar en vellón supone un problema real para las haciendas municipales. Generalmente, el principal inconveniente era el pago o desembolso que los municipios debían realizar por la reducción de vellón a plata ${ }^{48}$ o por el transporte del vellón procedido de la Santa Bula, que era entregada en las Juntas por un comisionado, elegido por el concejo a cambio de una cantidad:

"Yten dan en descargo aver pagado a Pedro de Cortaverria por tres vezes que a ydo a tres juntas particulares por nueve dias de ocupacion a quinientos maravedis ciento y treinta y dos reales con mas veinte y quatro reales que se pagaron por la lleva del vellon procedido de la bula" 49 .

La reducción de vellón a plata también era un inconveniente que debía padecer la Corona, porque las provisiones de dinero para Flandes, Italia, Aragón o Cataluña se tenían que hacer en plata, mientras que las recaudaciones de los contribuyentes se percibían en vellón, con lo que debían pagar a los asentistas que se encargaban de ello un

47 Archivo Municipal de Pasajes (AMP), C/2///1/2, Fol. $126 \mathrm{r}^{\circ}$.

48 "Yiten doi por descargo y retengo en mi ciento y veinte y ocho reales que he pagado en reducir treinta ducados de bellon a plata para ynbiar a poder del tesorero de esta provincia con mas treinta ducados en bellon para el socorro de los sodados de esta provincia..." (ArchivoMunicipal de Segura (AMS) C/2/3/6 1636-1637)

49 AMU, Cuentas Municipales, Leg. 2 (1633). 
premio por la operación de convertir la moneda de cobre en plata - lo que reducía el rendimiento obtenido de los impuestos $-{ }^{50}$.

\section{CONCLUSIONES}

Con respecto al premio de la plata, durante el siglo XVII encontramos dos comportamientos o modelos bien diferenciados:

- Costero: más cercano al comportamiento descrito para Sevilla y la Corte, gracias a su dinamismo comercial y a la abundancia de plata, lo que hace que los premios sean más bajos y haya un mayor desprecio por el vellón.

- Interior: los premios son más altos, pero dentro de este panorama, hay localidades que se acercan más al modelo costero, por estar cercanas a centros comerciales costeros, o ser ellos mismos centros dinamizadores de la economía local (Asteasu, Urrechu, Vergara). Cuanto más alejados están de estos centros, más alto es el valor y menor la circulación de plata.

De todas formas, los premios son diferentes en cada lugar, en respuesta al propio dinamismo económico de cada uno. Ello nos hace pensar en la autonomía de las economías locales, unas con respecto a otras, y en los ritmos diferenciados que presentan cada una de las localidades guipuzcoanas.

En Guipúzcoa los premios de la plata pagados parecen ser superiores a los aportados en los casos de Andalucía y Madrid, hasta aproximadamente 1660 . Los premios de la plata comienzan a ser aplicados más tarde y la estabilización parece llegar también más tarde, por motivos bélicos y político-estratégicos. Además en cada lugar el premio depende de la negociación entre particulares, lo que provoca que las oscilaciones puedan ser mayores.

Lo que queda claro es que todo depende del dinamismo económico y de la circulación de plata que exista en cada lugar, eso es lo que diferencia a Guipúzcoa del resto de la Corona, y, dentro de Guipúzcoa, a los lugares de la costa de los del interior. Por tanto, los datos no se pueden 
generalizar, puesto que en cada localidad las variaciones son diferentes y en cada villa en fechas concretas las oscilaciones son importantes; no es correcto generalizar, pues las variaciones son un síntoma de las peculiaridades económicas de cada caso. No se pueden seguir las tablas de Hamilton o de Serrano Mangas para este caso. De la misma forma, las medias o cantidades índice no son útiles y falsean la realidad.

En cuanto a las repercusiones prácticas, todos los autores coinciden en decir que, a nivel microeconómico, se produce una subida de los precios, relacionada con el poder adquisitivo de los salarios, y que, a nivel macroeconómico, la desconfianza y pérdida de valor de la moneda impidió el ahorro y, por tanto, las inversiones, dando lugar a la descapitalización de los sectores productivos, al descenso del crédito a particulares, al aumento de los costes de transporte y de la mano de obra, que afectará a la industria y acentuará la invasión de productos extranjeros ${ }^{51}$. Pero en el caso guipuzcoano no parece que las repercusiones fuesen tan profundas; téngase en cuenta que ésta era una economía - cara al exterior, no tanto al interior - más saneada y estable, en la que la industria del hierro o el comercio funcionaban generalmente en plata, lo que hace que las repercusiones sean escasas.

Donde realmente se pudieron notar las consecuencias de las alteraciones monetarias fue a nivel interno, en los mercados y transacciones locales. La plata se convirtió en objeto de mercadeo, además de en medio de pago; por eso, las repercusiones de la devaluación no afectan directamente al intermediario o comerciante, sino a los consumidores, que son quienes pagan en vellón y pierden poder adquisitivo. Como consecuencia de la negociación de las monedas emprendida por comerciantes e intermediarios, es el comprador el que más afectado se ve, porque es el vendedor el que establece el valor al cambio de la moneda de plata. El vendedor o intermediario es alguien que negocia en varios lugares donde el cambio es diferente -especulación monetaria- y acepta el premio de la plata que a él le conviene y resulta más rentable, en función de cómo esté en otros lugares o en la propia localidad. Al final, el consumidor es el que siente toda la presión de la devaluación, porque acaba pagando mayores precios - por la inflación salarial y de precios-.

51 Garcia Guerra, E.M., Alteraciones monetarias..., op. cit., pp. 646-647. 
El premio de la plata y la devaluación del vellón en Guipúzcoa en el siglo xvil

Tabla 1. Premio de la plata (Modelo Costero)

\begin{tabular}{|c|c|c|c|c|c|c|c|c|c|c|c|}
\hline & & & & & & Franja c & oster & & & & \\
\hline Años & Fuent & terrabía ${ }^{*}$ & $\% \#$ & & Pasajes & & & $\%$ & & Hernani & $\%$ \\
\hline 1629 & & & & & 1,25 & & & 25 & & & \\
\hline 1630 & & & & & 1,19 & & & 19 & & & \\
\hline 1631 & & & & & 1,15 & & & 15 & & & \\
\hline 1632 & & & & & & & & & & & \\
\hline 1633 & & & & & 1,307 & & & 31 & & & \\
\hline 1634 & & & & & 1,597 & & & 60 & & & \\
\hline 1635 & & & & & 1,25 & & & 25 & & & \\
\hline 1636 & & & & 1,25 & & 1,31 & 25 & & 31 & & \\
\hline 1637 & & & & & 1,2 & & & 20 & & & \\
\hline 1638 & & & & & 1,5 & & & 50 & & & \\
\hline 1639 & & & & & & & & & & & \\
\hline 1640 & & & & & 1,5 & & & 50 & & & \\
\hline 1641 & & & & $1,5 \quad 1,5$ & $562 \quad 1,37$ & $75 \quad 1,625$ & 50 & $56 \quad 38$ & 863 & & \\
\hline 1642 & & 2,5 & 150 & & & & & & & & \\
\hline 1643 & & & & & 1,25 & & & 25 & & & \\
\hline 1644 & & 1,25 & 25 & & 1,25 & & & 25 & & & \\
\hline 1645 & & 1,25 & 25 & $1,248 \quad 1,25$ & $25 \quad 1,26$ & $1,311,375$ & 25 & $26 \quad 31$ & 138 & & \\
\hline 1646 & & & & & 1,375 & & & 38 & & & \\
\hline 1647 & & & & & 1,375 & & & 38 & & & \\
\hline 1648 & & & & & 1,375 & & & 38 & & & \\
\hline 1649 & & & & 1,437 & & 1,49 & 44 & & 50 & & \\
\hline 1650 & 1,18 & 1,5 & $18 \quad 50$ & & 1,5 & & & 50 & & & \\
\hline 1651 & & & & & 1,5 & & & 50 & & & \\
\hline 1652 & 1,44 & 1,5 & $44 \quad 50$ & & 1,5 & & & 50 & & & \\
\hline 1653 & & & & & 1,5 & & & 50 & & & \\
\hline 1654 & & 1,5 & 50 & & & & & & & & \\
\hline 1655 & & 1,62 & 62 & & 1,5 & & & 50 & & & \\
\hline 1656 & & & & & & & & & & & \\
\hline 1657 & & & & & 1,5 & & & 50 & & 1,56 & 56 \\
\hline 1658 & & & & & 1,5 & & & 50 & & $1,74 \quad 1,5$ & $74 \quad 50$ \\
\hline 1659 & & & & & 1,5 & & & 50 & & $1,56 \quad 1,62$ & $56 \quad 62$ \\
\hline 1660 & & & & 1,431 & 1,56 & 1,625 & 43 & 56 & 63 & 1,62 & 62 \\
\hline 1661 & & & & & 1,625 & & & 63 & & & \\
\hline 1662 & & & & & 1,75 & & & 75 & & & \\
\hline 1663 & & & & & 1,75 & & & 75 & & 1,87 & 87 \\
\hline 1664 & & 2 & 100 & & & & & & & & \\
\hline 1665 & & & & & & & & & & & \\
\hline 1666 & & & & & 2,375 & & & 138 & & $2,252,375$ & $125 \quad 138$ \\
\hline 1667 & & & & & 2,375 & & & 138 & & & \\
\hline 1668 & & & & & 2,35 & & & 135 & & 2,375 & 138 \\
\hline 1669 & & & & & 2,75 & & & 175 & & & \\
\hline 1670 & & & & & 2,75 & & & 175 & & & \\
\hline 1671 & & & & & 2,5 & & & 150 & & 2,62 & 162 \\
\hline
\end{tabular}


Tabla 1. Premio de la plata (Modelo Costero) (continuación)

\begin{tabular}{|c|c|c|c|c|c|c|c|c|c|}
\hline \multirow[b]{2}{*}{ Años } & & \multicolumn{8}{|c|}{ Franja costera } \\
\hline & \multicolumn{2}{|c|}{ Fuenterrabia* } & $\% \#$ & \multicolumn{2}{|r|}{ Pasajes } & \multicolumn{2}{|r|}{$\%$} & \multirow{2}{*}{$\frac{\text { Hernani }}{2,75}$} & \multirow{2}{*}{$\frac{\%}{175}$} \\
\hline 1672 & & 77 & 177 & & 2,5 & & 150 & & \\
\hline 1673 & & & & 2,75 & 2,62 & 175 & 162 & 2,75 & 175 \\
\hline 1674 & 2,74 & 2,83 & $174 \quad 183$ & & 2,75 & & $\uparrow 75$ & & \\
\hline 1675 & 2,25 & 2,74 & $125 \quad 174$ & & 2,75 & & 175 & & \\
\hline 1676 & & & & & 2,75 & & 175 & & \\
\hline 1677 & & 77 & 177 & & 2,75 & & 175 & & \\
\hline 1678 & & & & & 2,75 & & 175 & & \\
\hline 1679 & & & & & 2,875 & & 188 & & \\
\hline 1680 & & & & & 1,5 & & 50 & & \\
\hline 1681 & & .5 & 50 & & & & & & \\
\hline 1682 & & 5 & 50 & & & & & & \\
\hline 1683 & 1,47 & 1,52 & $47 \quad 52$ & & 1,5 & & 50 & & \\
\hline 1684 & 1,52 & 1,59 & $52 \quad 59$ & & 1,5 & & 50 & & \\
\hline 1685 & &, 5 & 50 & & & & & & \\
\hline 1686 & &, 5 & 50 & & & & & & \\
\hline 1687 & & 5 & 50 & & & & & & \\
\hline 1688 & & & & & & & & 1,5 & 50 \\
\hline 1689 & &, 5 & 50 & & & & & 1,5 & 50 \\
\hline 1690 & & & & & & & & 1,5 & 50 \\
\hline 1691 & & 1,5 & 50 & & & & & 1,5 & 50 \\
\hline 1692 & & & & & & & & 1,5 & 50 \\
\hline 1693 & & & & & & & & 1,5 & 50 \\
\hline 1694 & &, 5 & 50 & & & & & 1,5 & 50 \\
\hline 1695 & & & & & & & & 1,5 & 50 \\
\hline 1696 & & & & & & & & 1,5 & 50 \\
\hline 1697 & &, 5 & 50 & & & & & 1,5 & 50 \\
\hline 1698 & & & & & & & & 1,5 & 50 \\
\hline 1699 & & & & & & & & 1,5 & 50 \\
\hline 1700 & &, 5 & 50 & & & & & & \\
\hline
\end{tabular}

Datos extraidos de: A.M. Fuenterrabia $C, 2,6$.
A.M.Pasajes $C, 2, I, 1,1$.
A.M.Hernani $C, 2,7$
C, $2,1,1,2$.
C. 2,8
C, $2,1,1,3$
C. $2,1,1,4$
C, 2,9 .
C, $2,1,2,1$.
C. $2,1,2,2$
C, $2,1,2,3$.
C, 2,10
C, 2,12

C, $2,7,1$ y 2 .

$\mathrm{C}, 2,8$.

C, 2,9 .

C, 2,10 .

C, 2,12 .

* Premio de la plata en vellón: cantidad de vellón de premio por cada unidad de plata. En el caso de 1642 por cada real de plata se dan 2'5 reales de vellón.

\# Premio de la plata en tanto por ciento. 
Tabla 2. Premio de la plata (Modelo Interior-Cuenca del Oria)

\begin{tabular}{|c|c|c|c|c|c|c|c|c|c|c|c|c|}
\hline \multirow[b]{2}{*}{ Años } & \multicolumn{12}{|c|}{ Cuenca del Oria } \\
\hline & Asteasu & $\%$ & \multicolumn{2}{|c|}{ Ordicia } & \multicolumn{2}{|c|}{$\%$} & \multicolumn{3}{|c|}{ Segura } & \multicolumn{3}{|c|}{$\%$} \\
\hline \multicolumn{13}{|l|}{1629} \\
\hline \multicolumn{13}{|l|}{1630} \\
\hline \multicolumn{13}{|l|}{1631} \\
\hline 1632 & & & & & & & 1,3125 & 1,23 & 1,25 & 31 & 23 & 25 \\
\hline 1633 & & & & & & & \multicolumn{3}{|c|}{1,291} & \multicolumn{3}{|c|}{29} \\
\hline 1634 & & & & & & & 1 & & 1,27 & 0 & & 27 \\
\hline 1635 & & & & & & & \multicolumn{3}{|c|}{1,25} & \multicolumn{3}{|c|}{25} \\
\hline \multicolumn{13}{|l|}{1636} \\
\hline 1637 & 1,25 & 25 & & & & & \multicolumn{3}{|c|}{1,375} & \multicolumn{3}{|c|}{38} \\
\hline 1638 & & & & & & & \multicolumn{3}{|c|}{1,56} & \multicolumn{3}{|c|}{56} \\
\hline \multicolumn{13}{|l|}{1639} \\
\hline \multicolumn{13}{|l|}{1640} \\
\hline 1641 & 1,75 & 75 & & & & & & & & & & \\
\hline 1642 & 1,5 & 50 & 1,375 & 1,5 & 38 & 50 & 1,875 & 2,5 & 3,125 & 88 & 150 & 213 \\
\hline 1643 & 1,25 & 25 & 1,7 & & 7 & & & 1,375 & & & 38 & \\
\hline 1644 & & & & & & & & & & & & \\
\hline 1645 & & & & & & & & & & & & \\
\hline 1646 & 1,375 & 38 & & & & & & & & & & \\
\hline 1647 & & & 1,3 & & 3 & & & & & & & \\
\hline 1648 & 1,34 & 34 & & & & & & 1,5 & & & 50 & \\
\hline 1649 & & & & & & & & 1,5 & & & 50 & \\
\hline 1650 & 1,42 & 42 & 1,3 & & 3 & & & & & & & \\
\hline 1651 & & & 1 & & & & & & & & & \\
\hline 1652 & 1,5 & 50 & & & & & & & & & & \\
\hline 1653 & 1,56 & 56 & & & & & & 1,5 & & & 50 & \\
\hline 1654 & 1,56 & 56 & & & & & & & & & & \\
\hline 1655 & & & 1 & & 5 & & & 1,5 & & & 50 & \\
\hline 1656 & 1,62 & 62 & & 1,56 & 50 & 56 & & & & & & \\
\hline 1657 & & & 1,6 & & & & & & & & & \\
\hline 1658 & 1,64 & 64 & 1,6 & & & & & & & & & \\
\hline 1659 & & & 1,625 & 1,75 & 63 & 75 & & & & & & \\
\hline 1660 & 1,5 & 50 & & & & & & & & & & \\
\hline 1661 & 1,75 & 75 & & & & & & & & & & \\
\hline 1662 & & & & & & & & & & & & \\
\hline 1663 & 1,78 & 78 & & & & & & & & & & \\
\hline 1664 & & & & & & & & 2,125 & & & 113 & \\
\hline 1665 & 1,75 & 75 & & & & & & & & & & \\
\hline 1666 & 2,375 & 138 & & & & & & & & & & \\
\hline 1667 & 2,5 & 150 & & & & & & & & & & \\
\hline 1668 & 2,5 & 150 & & & & & & & & & & \\
\hline 1669 & 2,75 & 175 & & & & & & & & & & \\
\hline 1670 & 2,75 & 175 & & & & & & & & & & \\
\hline 1671 & 2,625 & 163 & & & & & & & & & & \\
\hline
\end{tabular}


Tabla 2. Premio de la plata (Modelo Interior-Cuenca del Oria) (cont.)

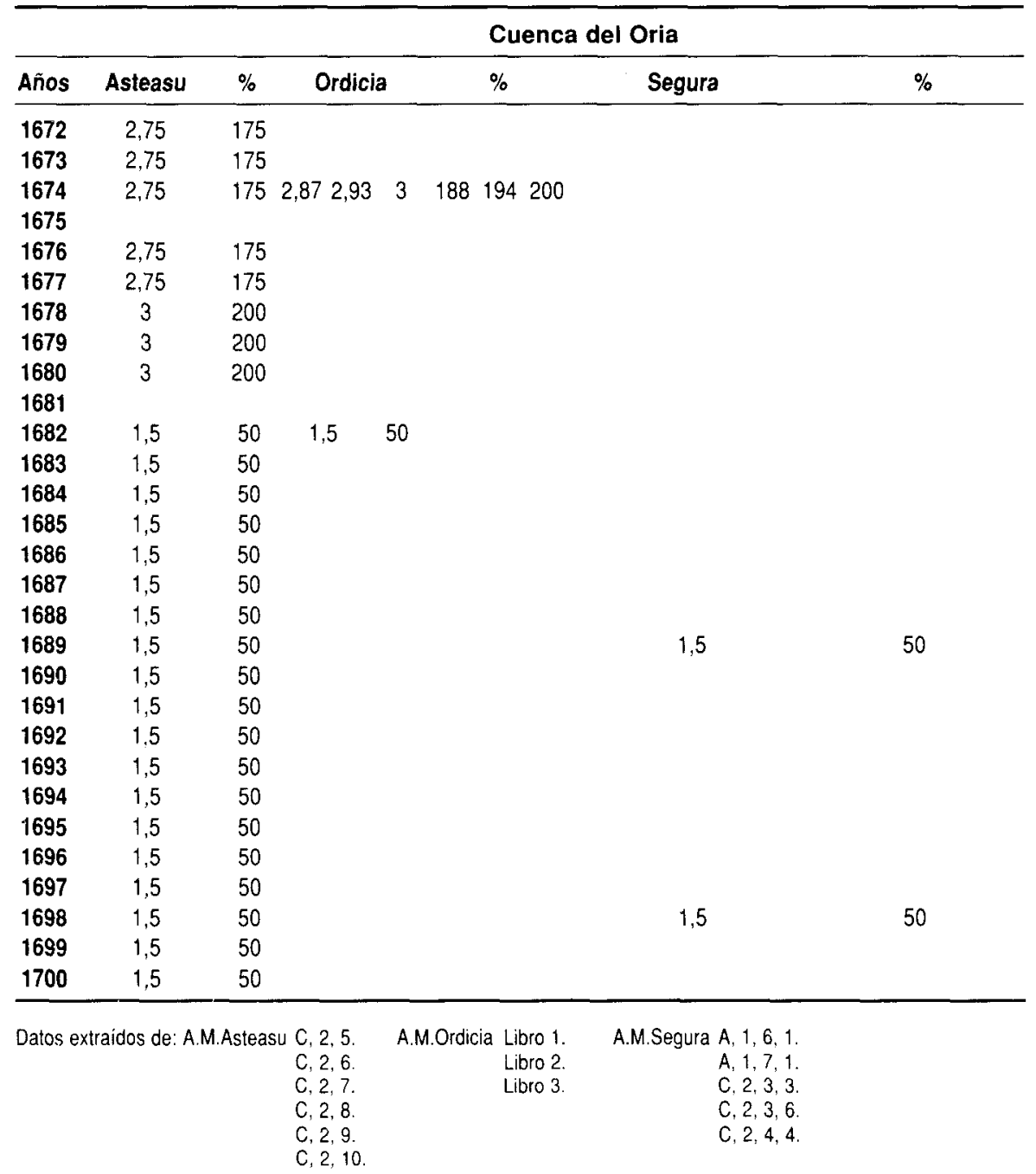


El premio de la plata y la devaluación del vellón en Guipúzcoa en el siglo xvil

Tabla 3. Premio de la plata (Modelo Interior-Cuenca del Urola)

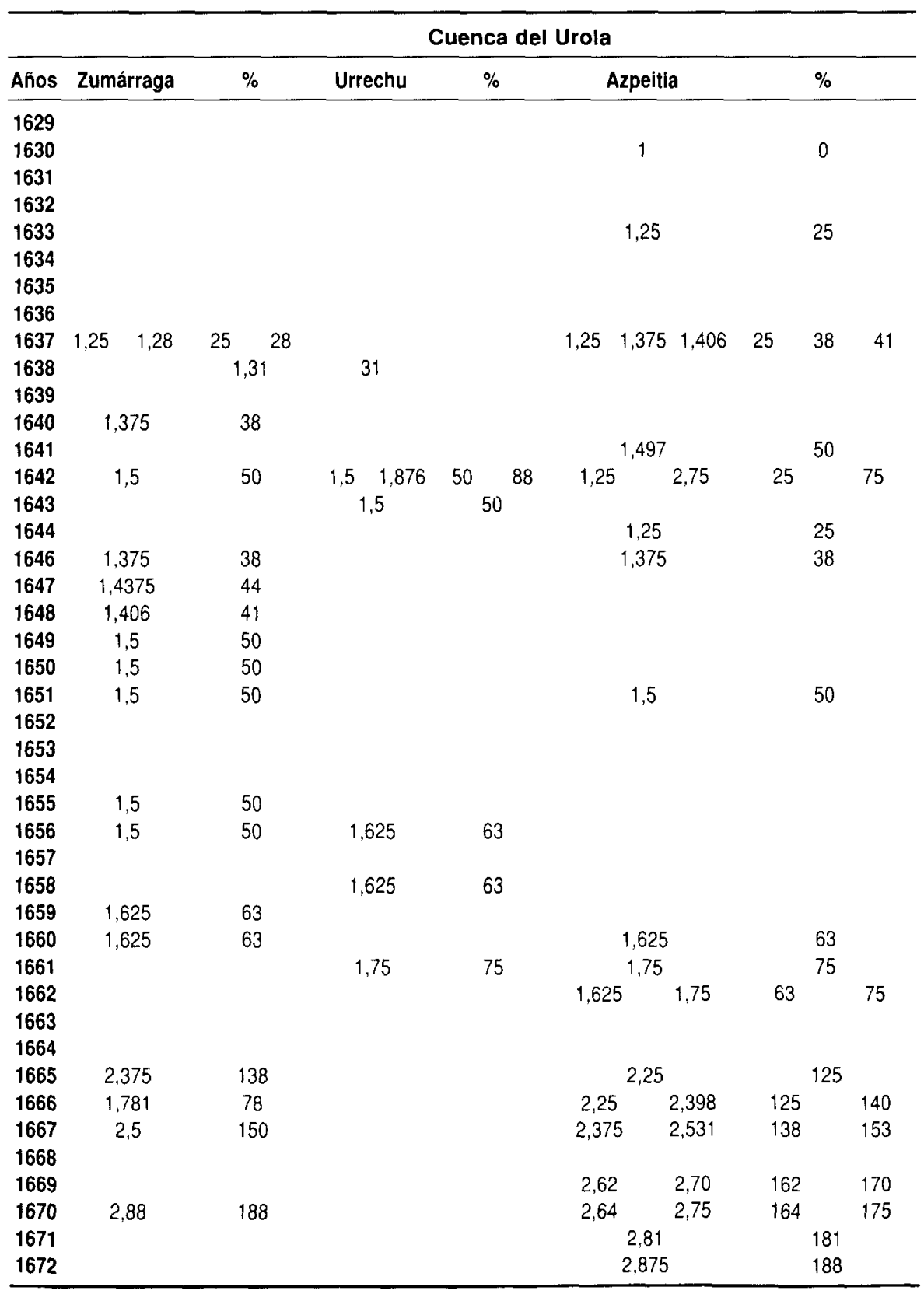


Tabla 3. Premio de la plata (Modelo Interior-Cuenca del Urola) (cont.)

\begin{tabular}{|c|c|c|c|c|c|c|c|c|c|c|}
\hline \multirow{3}{*}{$\frac{\text { Años }}{1673}$} & \multicolumn{10}{|c|}{ Cuenca del Urola } \\
\hline & \multirow{2}{*}{$\frac{\text { Zumárraga }}{2,875}$} & \multirow{2}{*}{$\frac{\%}{188}$} & \multirow[t]{3}{*}{ Urrechu } & \multirow[t]{3}{*}{$\%$} & \multicolumn{3}{|c|}{ Azpeitia } & \multicolumn{3}{|c|}{$\%$} \\
\hline & & & & & \multirow[t]{2}{*}{1,45} & \multirow{2}{*}{$\begin{array}{c}2,36 \\
2,875\end{array}$} & \multirow[t]{2}{*}{2,875} & \multirow[t]{2}{*}{45} & \multirow{2}{*}{$\begin{array}{l}136 \\
188\end{array}$} & \multirow[t]{2}{*}{188} \\
\hline 1674 & $2 \quad 2,5$ & $100 \quad 150$ & & & & & & & & \\
\hline 1675 & 3 & 200 & 2,875 & 188 & \multicolumn{3}{|c|}{2,875} & & 188 & \\
\hline 1676 & 2,81 & 181 & 3 & 200 & \multicolumn{3}{|c|}{2,875} & & 188 & \\
\hline 1677 & & & 3,295 & 230 & \multicolumn{3}{|c|}{3} & & 200 & \\
\hline 1678 & & & & & \multicolumn{3}{|c|}{3} & & 200 & \\
\hline 1679 & & & & & \multicolumn{3}{|c|}{3,125} & & 213 & \\
\hline 1680 & 1,5 & 50 & & & \multicolumn{3}{|c|}{3} & & 200 & \\
\hline 1681 & & & & & \multicolumn{3}{|c|}{1,49} & & 50 & \\
\hline \multicolumn{11}{|l|}{1682} \\
\hline 1683 & 1,5 & 50 & & & & & & & & \\
\hline 1684 & & & & & \multicolumn{3}{|c|}{1,5} & & 50 & \\
\hline 1685 & & & & & \multicolumn{3}{|c|}{1,5} & & 50 & \\
\hline 1686 & & & & & \multicolumn{3}{|c|}{1,5} & & 50 & \\
\hline 1687 & & & & & \multicolumn{3}{|c|}{1,5} & & 50 & \\
\hline 1688 & & & & & \multicolumn{3}{|c|}{1,5} & & 50 & \\
\hline 1689 & & & & & \multicolumn{3}{|c|}{1,5} & & 50 & \\
\hline 1690 & & & & & \multicolumn{3}{|c|}{1,5} & & 50 & \\
\hline 1691 & & & & & & 1,5 & & & 50 & \\
\hline 1692 & & & & & & & & & & \\
\hline 1693 & & & & & & 1,5 & & & 50 & \\
\hline 1694 & & & & & & & & & & \\
\hline 1695 & & & & & & 1,5 & & & 50 & \\
\hline 1696 & & & & & & & & & & \\
\hline 1697 & & & & & & & & & & \\
\hline 1698 & & & & & & & & & & \\
\hline 1699 & & & & & & 1,5 & & & 50 & \\
\hline 1700 & & & & & & 1,5 & & & 50 & \\
\hline
\end{tabular}

Datos extraídos de: A.M.Zumárraga $C, 2,1,1 . \quad$ A.M.Urrechu Cuentas, Leg. 2.
$C, 2,2,1$.

A.M.Azpeitia 320/764-01. $320 / 751-35$ al 37 $320 / 758-04$ 320/763-03. $320 / 760-01$ al 09 
Tabla 4. Premio de la plata (Modelo Interior-Cuenca del Deva)

\begin{tabular}{|c|c|c|c|c|c|}
\hline \multicolumn{6}{|c|}{ Cuenca del Deva } \\
\hline Años & \multicolumn{2}{|c|}{ Vergara } & \multicolumn{3}{|c|}{$\%$} \\
\hline 1629 & & & & & \\
\hline 1630 & & & & & \\
\hline 1631 & & & & & \\
\hline 1632 & \multicolumn{2}{|c|}{1,1895} & \multicolumn{3}{|c|}{19} \\
\hline 1633 & & & & & \\
\hline 1634 & & & & & \\
\hline 1635 & \multicolumn{2}{|c|}{1,25} & \multicolumn{3}{|c|}{25} \\
\hline 1636 & & & & & \\
\hline 1637 & \multirow{2}{*}{\multicolumn{2}{|c|}{1,378}} & & & \\
\hline 1638 & & & \multicolumn{3}{|c|}{38} \\
\hline \multirow{2}{*}{\multicolumn{6}{|c|}{$\begin{array}{l}1639 \\
1640\end{array}$}} \\
\hline & & & & & \\
\hline \multicolumn{6}{|l|}{1641} \\
\hline \multicolumn{6}{|l|}{1642} \\
\hline \multicolumn{6}{|l|}{1643} \\
\hline \multicolumn{6}{|l|}{1644} \\
\hline \multicolumn{6}{|l|}{1645} \\
\hline \multicolumn{6}{|l|}{1646} \\
\hline \multicolumn{6}{|l|}{1647} \\
\hline \multicolumn{6}{|l|}{1648} \\
\hline \multicolumn{6}{|l|}{1649} \\
\hline \multicolumn{6}{|l|}{1650} \\
\hline \multicolumn{6}{|l|}{1651} \\
\hline \multicolumn{6}{|l|}{1652} \\
\hline \multicolumn{6}{|l|}{1653} \\
\hline \multicolumn{6}{|l|}{1654} \\
\hline 1655 & & & & & \\
\hline 1656 & & & & & \\
\hline 1657 & & & & & \\
\hline 1658 & & & & & \\
\hline 1659 & & & & & \\
\hline 1660 & & & & & \\
\hline 1661 & & & & 138 & \\
\hline 1662 & & & & & \\
\hline 1663 & & & & & \\
\hline 1664 & & & & & \\
\hline 1665 & 1,331 & 2,25 & 33 & & 125 \\
\hline 1666 & & & & 138 & \\
\hline 1667 & & & & & \\
\hline 1668 & & & & 157 & \\
\hline 1669 & & & & 157 & \\
\hline 1670 & & & & 163 & \\
\hline
\end{tabular}

Datos extraidos de: A.M.Vergara, Libros de cuentas, L/121 Cuentas Municipales, L/80 al L/93. Libros de cuentas, L/074 
Tabla 5. Premio de la plata (E.J. Hamilton y Serrano Mangas)

\begin{tabular}{|c|c|c|c|c|}
\hline Años & Andalucia & $\begin{array}{l}\text { Castilla la Nueva } \\
\text { Promedio Anual (\%) }\end{array}$ & Cas. la Vieja-León & $\begin{array}{c}\text { Madrid } \\
\text { Media Anual (\%) }\end{array}$ \\
\hline 1618 & & & & 2,13 \\
\hline 1619 & 2,72 & & & \\
\hline 1620 & 4 & 3,81 & 5,06 & 4 \\
\hline 1621 & 4 & 4,96 & 3,18 & 4,63 \\
\hline 1622 & 5,48 & 5,79 & 5,67 & 5,71 \\
\hline 1623 & 9,73 & 10,15 & 11,32 & 9,4 \\
\hline 1624 & 11,45 & 12,2 & 13,3 & 16,11 \\
\hline 1625 & 12,25 & 23,29 & 25,8 & 40,79 \\
\hline 1626 & 40,94 & 49,04 & 54,75 & 54,76 \\
\hline 1627 & 37,1 & 42,13 & 50,94 & 58,45 \\
\hline 1628 & 36,56 & 37,36 & 34,93 & 47,59 \\
\hline 1629 & 16,81 & 18,2 & 15,1 & 14,68 \\
\hline 1630 & 21,15 & 20,6 & 20,29 & 23,01 \\
\hline 1631 & 19,25 & 18,48 & 18,28 & 14,81 \\
\hline 1632 & 18,5 & 18,38 & 18,63 & 16,92 \\
\hline 1633 & 22,91 & 24,09 & 22,59 & 24,71 \\
\hline 1634 & 27,38 & 26,4 & 25,13 & 28,5 \\
\hline 1635 & 25,31 & 27,82 & 27,1 & 27,19 \\
\hline 1636 & 25,15 & 27,64 & 25,57 & 26,71 \\
\hline 1637 & 29,39 & 28,68 & 29,36 & 32 \\
\hline 1638 & 35,75 & 31,72 & 35,55 & 35,46 \\
\hline 1639 & 31,9 & 34,92 & 38,8 & 38,57 \\
\hline 1640 & 48 & 46,81 & 39,24 & 37,86 \\
\hline 1641 & 62,69 & 64,7 & 69,88 & 77,59 \\
\hline 1642 & 120,62 & 120,5 & 132,25 & 124,87 \\
\hline 1643 & 32,92 & 26,25 & 25,74 & 30,27 \\
\hline 1644 & 32,29 & 29,9 & 28,08 & 30,5 \\
\hline 1645 & 35,81 & 35,38 & 27,05 & 33,25 \\
\hline 1646 & 41,18 & 39,83 & 35,28 & 34,42 \\
\hline 1647 & 39,48 & 34,59 & 40,19 & 38,75 \\
\hline 1648 & 41,04 & 39,86 & 43,24 & 42,83 \\
\hline 1649 & 43,32 & 43,62 & 48,6 & 50 \\
\hline 1650 & 50,06 & 52,13 & 49,88 & 50 \\
\hline 1651 & & & & 50 \\
\hline 1652 & & & & 50 \\
\hline 1653 & & & & 50 \\
\hline 1654 & & & & 50 \\
\hline 1655 & & & & 50 \\
\hline 1656 & & & & 50 \\
\hline 1657 & & & & 56,26 \\
\hline 1658 & & & & 64,9 \\
\hline 1659 & & & & 64,85 \\
\hline 1660 & & & & 63,54 \\
\hline
\end{tabular}


El premio de la plata y la devaluación del vellón en Guipúzcoa en el siglo xvil

Tabla 5. Premio de la plata (E.J. Hamilton y Serrano Mangas) (cont.)

\begin{tabular}{|c|c|c|c|c|}
\hline Años & Andalucia & $\begin{array}{l}\text { Castilla la Nueva } \\
\text { Promedio Anual (\%) }\end{array}$ & Cas. la Vieja-León & $\begin{array}{c}\text { Madrid } \\
\text { Media Anual (\%) }\end{array}$ \\
\hline 1618 & & & & 2,13 \\
\hline 1661 & & & & 66,16 \\
\hline 1662 & & & & 79,69 \\
\hline 1663 & & & & 98,55 \\
\hline 1664 & & & & 109,14 \\
\hline 1665 & & & & 92,36 \\
\hline 1666 & & & & 124,37 \\
\hline 1667 & & & & 126,18 \\
\hline 1668 & & & & 132,94 \\
\hline
\end{tabular}

Datos extraídos de: Hamilton, E.J., El tesoro americano y la revolución de los precios en España, Barcelona, Ariel, 1983, p. 108 y Serrano Mangas, F., Vellón y metales preciosos en la corte del rey de España (1618-1668), Madrid, Banco de Espaก̃a, 1996, p. 105. 